\title{
Conversas entre o Modelo dos Campos Semânticos e a Psicologia Econômica na leitura do processo de tomada de decisão envolvendo trocas intertemporais em Ambientes de Educação Financeira Escolar
}

\author{
Ivail Muniz Jr \\ Colégio Pedro II; FAETEC; COPPE/UFRJ \\ ivailmuniz@gmail.com
}

\begin{abstract}
Resumo
Esse artigo apresenta um recorte de uma investigação da produção de significados de um grupo de estudantes de Ensino Médio envolvendo trocas intertemporais relacionadas à tomada de decisão, relacionadas ao problema clássico de se comprar à vista com desconto ou a prazo "sem juros". Para analisar a tomada de decisão dos participantes, utilizam-se duas lentes teórico-metodológicas: o Modelo dos Campos Semânticos e alguns estudos sobre aversão a perdas e efeitos de enquadramento, oriundos da Psicologia Econômica. Os resultados apontam para uma interligação, conexão, aderência entre os aspectos matemáticos e não matemáticos na tomada de decisão dos estudantes; para o surgimento de alternativas para além das opções apresentadas e ainda para a emergência de posicionamentos críticos sobre taxas de juros cobradas em financiamentos e na forma como opções de pagamento são intencionalmente apresentadas.
\end{abstract}

Palavras-chave: Ambientes de Educação Financeira Escolar. Tomada de decisão. Modelo dos campos semânticos. Efeitos de enquadramento. Trocas intertemporais.

\section{Conversations between the Semantic Field Model and Economic Psychology in reading the decision-making process involving intertemporal exchanges in School Financial Education Environments}

\begin{abstract}
This paper presents a cross-section of an investigation of the meanings production of a group of high school students involving intertemporal exchanges related to the decision making, related to the classic problem of buying cash with a discount or term "without interest". Two theoretical and methodological lenses are used to analyze participants' decision-making: the Semantic Fields Model and some studies on aversion to losses and framing effects from Economic Psychology. The results point to an interconnection, connection, adherence between mathematical and non-mathematical aspects in student decision-making; for the emergence of alternatives beyond the options presented and also for the emergence of critical positions on interest rates charged on financing and on the way payment options are intentionally presented.
\end{abstract}

Keywords: School Financial Education Environments. Decision Making. Model of semantic fields. Framing effects. Intertemporal exchanges. 


\section{Introdução}

A abordagem de situações econômico-financeiras (SEF) na educação básica tem sido cada vez mais alvo de pesquisas em Educação Matemática no Brasil e no Mundo, principalmente nos últimos 10 anos, e geralmente aparecem associadas à Matemática Financeira presente nos livros didáticos de matemática para o Ensino Médio no Brasil, ou a algum tipo de concepção ou proposta de Educação Financeira nas Escolas conforme apontam, por exemplo, Saito (2008), Rolim e Motta (2014), Silva e Powell (2013), Pessoa (2016), Xu e Zia (2012), Aprea et al. (2016).

Apesar desse crescimento, os estudos específicos sobre a tomada de decisão em Ambientes de Educação Financeira Escolar (AEFE) ${ }^{1}$ são poucos, conforme podemos ver em Campos (2013) e Muniz (2016a). Além disso, identificamos que os estudos da Psicologia Econômica sobre tomada de decisão, incluindo as envolvendo trocas intertemporais ${ }^{2}$, não costumam ser levados em consideração na fundamentação teórica e nem na metodologia de análise nas pesquisas relacionadas com Educação Financeira Escolar, sendo uma exceção o trabalho de Muniz (2016a).

Este artigo apresenta uma investigação dos significados produzidos por seis estudantes de Ensino Médio para trocas intertemporais presentes em uma situação financeira muito comum ao consumidor brasileiro, em que são oferecidas duas opções de pagamento para um produto: pagar à vista com desconto, ou a prazo em duas vezes sem juros, ambas considerando o valor anunciado pelo vendedor. Tal investigação é um recorte de nossa pesquisa de doutorado, intitulada Econs ou Humanos? Um estudo sobre a tomada de decisão em ambientes de educação financeira escolar (MUNIZ, 2016a), de natureza qualitativa e do tipo etnográfica, realizada em três fases, contando com a participação de 40 estudantes ao todo, de duas escolas públicas do Rio de Janeiro, cuja fase de campo foi realizada nos anos de 2015 e 2016.

Essa pesquisa de Muniz (2016) buscou trazer algumas respostas, ainda que parciais e limitadas aos AEFE produzidos, para questões como: será que os alunos tomam decisões financeiras em AEFE, usando aspectos matemáticos, em especial os relacionados à matemática financeira, que acabaram de aprender na escola? Como são as operações e a lógica das operações usadas por eles

\footnotetext{
${ }^{1}$ Usaremos esse termo para representar os momentos de interação entre pessoas quando analisam situações econômicofinanceiras, em espaços escolares, visando ou envolvendo o ensino e aprendizagem, como também visando a pesquisa acadêmica, em especial a educacional. Assim, ambiente não se refere a lugares, a espaços escolares, a ambientes físicos e sim a momentos de interação. É para a atividade (LEONTIEV, 1984) de produzir significados a partir das situações econômico-financeiras abordadas que compõem cada tarefa, que fizemos nossa análise. Reforçamos que as atividades ocorrem em AEFE, e são nesses ambientes que a tomada de decisão é investigada. Não é a tomada de decisão na rua, no supermercado, nas lojas, nas concessionárias, ou em outros momentos, mas sim a tomada de decisão por estudantes de ensino médio nos AEFE criados nos encontros.

${ }^{2}$ Sinteticamente, as trocas intertemporais são escolhas dentre opções situadas em diferentes momentos no tempo, que estão associadas a sacrifícios e benefícios. Usufruir de um benefício agora, para fazer um ou mais sacrifícios depois, como por exemplo, comprar um pacote de viagens hoje para pagar depois em algumas parcelas, é um dos muitos exemplos de trocas intertemporais. Essa noção vem da perspectiva de Eduardo Giannetti (2005).
} 
para trabalhar com as informações apresentadas e com os objetos por eles constituídos? Que outros aspectos não matemáticos eles levaram em consideração na tomada de decisão?

Para isso utilizamos duas lentes: o Modelo dos Campos Semânticos (LINS, 1999; 2013) e os estudos da Psicologia Econômica, em especial os de Thaler (2008) e Kahneman (2012), em uma tentativa de ler o outro, para tentar identificar de quais lugares falavam. Explicaremos mais à frente qual foi o papel de cada uma dessas lentes nessa investigação.

Pretendemos assim dar uma contribuição para a ampliação da visão da tomada de decisão em SEF e de como isso pode ser importante para o ensino e aprendizagem de matemática e da Educação Financeira em espaços escolares.

\section{O papel do MCS e da Psicologia Econômica em nossa investigação sobre tomada de decisão}

Como dito na introdução, nossa pesquisa se ocupa em investigar aspectos matemáticos e não matemáticos usados por estudantes de Ensino Médio para tomar decisões envolvendo situações financeiras, apresentadas por meio de tarefas. Esse processo dos estudantes envolve a produção de significados e conhecimentos.

Para isso, assumimos concepções epistemológicas baseadas no Modelo dos Campos Semânticos (MCS), conforme proposto por Lins (1999). Nossa concepção de conhecimento vem desse modelo, em que o conhecimento não pode ser transmitido aos indivíduos, mas sim produzido pelo sujeito a partir da produção de significados. Segundo Lins (1999, p. 81), "conhecimento é uma crença-afirmação junto com uma justificação que o autoriza a produzir aquela enunciação".

Por exemplo, consideremos dois sujeitos hipotéticos, $\mathrm{S}_{1}$ e $\mathrm{S}_{2}$, e a seguinte SEF:

Paulo precisou tomar um empréstimo de 1000 reais a uma taxa de $10 \%$ ao mês (cheque especial), devido a sucessivos atrasos no pagamento de seu salário. Após 2 meses quitou a dívida, quando enfim conseguiu receber seu décimo terceiro (ainda que também atrasado). Quanto pagou para quitar essa dívida?

O quadro abaixo mostra os conhecimentos produzidos pelos dois sujeitos.

Quadro 1 - Diferentes conhecimentos a partir de diferentes justificações.

\begin{tabular}{|c|l|l|}
\hline & \multicolumn{1}{|c|}{ Crença-afirmação } & \multicolumn{1}{c|}{ Justificação } \\
\hline \multirow{2}{*}{$\mathrm{S}_{1}$} & $\begin{array}{l}\mathrm{VF}=\mathrm{VP} .(1+\mathrm{i})^{2} \\
\mathrm{VF}=1000 \mathrm{x}(1+10 \%)^{2}=1210 .\end{array}$ & $\begin{array}{l}\text { Apliquei a fórmula de Juros Compostos que o } \\
\text { professor ensinou lá no Ensino Médio. }\end{array}$ \\
\hline \multirow{3}{*}{$\mathrm{S}_{2}$} & $\begin{array}{l}1000+10 \% \text { de } 1000=1100 \\
1100+10 \% \text { de } 1000=1210 \\
\mathrm{VF}=1210 .\end{array}$ & $\begin{array}{l}\text { Fiz juros sobre juros, com a porcentagem de 10\%, até } \\
\text { chegar ao final, parecido com um exemplo que vi no } \\
\text { livro de matemática. }\end{array}$ \\
\hline
\end{tabular}

Fonte: Muniz (2016, p. 144) 
A justificação, nessa formulação, é parte integrante do conhecimento, e não apenas uma "explicação" para eles. A justificação é o que garante que aquela crença-afirmação possa ser enunciada pelo sujeito do conhecimento. Mesmo nos casos em que a justificação não é enunciada, como costuma acontecer fora da vida acadêmica, o fato de que um sujeito produz conhecimento pressupõe uma legitimidade na qual ele se apoia, ou seja, sua justificação. A justificação pode inclusive ser da seguinte forma: "sempre fiz assim e pela minha experiência funciona", ou "passa para o outro lado e troca o sinal, porque o professor disse que era pra fazer assim", ou, ainda, quando um especialista em finanças afirma que "considerando um retorno esperado pelo mercado de $25 \%$ ao ano e uma rentabilidade livre de risco de $14,25 \%$ a.a., o retorno mínimo desejado pelos acionistas para investir em determinada empresa de Beta 1,2 é igual a 27,15\% a.a., conforme o modelo CAPM de Sharpe e Lintner".

No que diz respeito ao que é significado de um objeto, usamos a noção de que é aquilo que efetivamente se diz a respeito desse objeto no interior de uma atividade, e objeto é aquilo para o que se produz significado.

Assim, quando uma pessoa se propõe a produzir significados para algum tipo de informação (o resíduo de uma enunciação), observamos, da perspectiva do MCS, o desencadeamento de um processo - o processo de produção de significados - o qual, segundo Silva (2003, p. 66), envolve:

(i) a constituição de objetos - coisas sobre as quais sabemos dizer algo e dizemos - que nos permite observar tanto os novos objetos que estão sendo constituídos quanto os significados produzidos para esses objetos;

(ii) a formação de um núcleo: o processo que envolve as estipulações locais, as operações e sua lógica;

(iii) a fala (ações enunciativas) na direção de interlocutores;

(iv) as legitimidades, isto é, o que é legítimo ou não dizer no interior de uma atividade.

Essa lista de noções-categoria apresentadas não sugere uma sequência do que acontece no processo, ou uma ordem de leitura.

Nessa ótica, quando temos atividades envolvendo situações financeiras, por exemplo, podemos constituir em objetos matemáticos o termo de uma PA ou PG, o crescimento exponencial, a soma de termos de uma progressão geométrica, etc, e em objetos financeiros o valor futuro de uma quantia, uma série uniforme, a taxa de retorno ou desconto, a inflação, a noção de equivalência de capitais, dentre outros. É a partir desses objetos que os estudantes realizam operações, baseadas em lógicas que também queremos investigar.

Segundo Lins e Gimenes (1997, p.114), “toda operação é realizada segundo uma lógica, e que é essencial investigar essas lógicas se queremos entender as formas de pensar de nossos alunos". 
O MCS apresenta muitas outras noções e elementos, mas aqui, neste texto, nos limitaremos a falar daquelas que efetivamente usaremos em nossa análise.

A Psicologia Econômica entra aqui para nos ajudar a entender de forma mais ampla a tomada de decisão humana. Mas o que essa área tem a ver com situações financeiras que, aparentemente, parecem ser apenas problemas de matemática financeira?

Os psicólogos Daniel Kahneman e Amos Tversky e, a partir deles, outros pesquisadores, identificaram que os seres humanos, ao tomar decisões das mais variadas e fazerem julgamentos sob incerteza, costumam utilizar alguns atalhos mentais denominados heurísticas ${ }^{3}$ e tendências (vieses), que levam os indivíduos a se desviarem das decisões que seriam as tomadas segundo um processo exclusivamente racional, ou seja, baseado exclusivamente na compreensão e utilização de toda informação disponível e orientado à otimização dos resultados financeiros.

Um exemplo dos desvios que as pessoas sistematicamente tomam são os efeitos de enquadramento. Os efeitos de enquadramento (KAHNEMAN, 2012) influenciam nossas decisões de acordo com a semântica na qual as opções são apresentadas. Por exemplo, apresentar um preço de tabela de mil reais com desconto à vista de $10 \%$, ou a alternativa de duas vezes "sem juros" de 500 reais costuma ser considerado mais atrativo, do que apresentar o preço do mesmo produto como 900 à vista e um parcelamento em duas vezes de 500 reais. As duas situações são equivalentes do ponto de vista econômico, mas são enquadradas como diferentes pelos consumidores, incluindo alunos de Ensino Médio. Em síntese, a forma como uma situação é apresentada pode interferir fortemente na tomada de decisão das pessoas, ainda que as opções sejam financeiramente equivalentes.

Assim, essa área nos forneceu possibilidades de compreensão de significados não matemáticos produzidos pelos estudantes, referentes aos efeitos de formulação (KAHNEMAN, 2012, p. 549) das opções de compra e sobre o que disseram sobre as taxas de juros embutidas nas opções de compra, as quais são intencionalmente apresentadas como benefícios e não como perdas aos consumidores.

Reforçamos, portanto, que o estudo do comportamento humano por pesquisadores dessa área denominada Psicologia Econômica, aqui recortado e utilizado de forma bem simples, é de fundamental importância para uma EFE que, de fato, trate as decisões humanas como de fato elas costumam ser, ou seja, caracterizadas por processos complexos, repletos de atalhos mentais, ora baseadas na consciência, ora não, que se misturam com processos analíticos e deliberados, em que os aspectos matemáticos são levados em consideração.

\footnotetext{
${ }^{3}$ Nesse texto, a partir da perspectiva do psicólogo Daniel Kahneman, vamos considerar heurística como sendo um procedimento simples que a ajuda a encontrar respostas adequadas, ainda que geralmente imperfeitas, para perguntas difíceis. A palavra vem da mesma raiz de heureca (KAHNEMAN, 2012, p. 127).
} 


\section{Metodologia}

O grupo investigado era formado por seis estudantes $(n=6)$ da terceira série do Ensino Médio de uma escola pública, situada na cidade do Rio de Janeiro. Este texto se caracteriza como um recorte de nossa pesquisa de doutorado (MUNIZ, 2016), de natureza qualitativa e do tipo etnográfica, realizada em três fases, contando com a participação de 40 estudantes ao todo, de duas escolas públicas, cuja fase de campo foi realizada nos anos de 2015 e 2016. Apresentaremos a análise do encontro 6, envolvendo uma tarefa que era composta por uma situação financeira inicial seguida de seis perguntas que buscavam convidar os estudantes a produzirem significados para algumas tomadas de decisão, bem como falar sobre os aspectos que levariam em consideração em suas tomadas de decisão, permitindo assim nossa análise sobre os significados produzidos nesse processo. A Figura 1 ilustra essa tarefa.

Figura 1 - Tarefa sobre trocas intertemporais entre comprar à vista ou a prazo e as taxas de juros embutidas

TAREFA 8 - Tomada de decisão e taxas de juros

Você tem duas opções de pagamento para comprar um produto indispensável para o seu trabalho, cujo preço de tabela é 1000 reais.

Opção I- Pagar à vista com $10 \%$ de desconto.

Opção II - Pagar a prazo, em duas vezes sem juros, ou seja, em duas de 500 reais, sendo a primeira para 30 e a outra para 60 dias. (Sistema $0+2$ ).

a) Qual a melhor decisão para você?

b) o que você faria: compraria à vista ou a prazo? Apresente que aspectos poderiam interferir em sua tomada de decisão.

c) Comparando o valor à vista com o fluxo de pagamentos a prazo, você acha que a loja está cobrando juros? Justifique sua resposta.

d) Qual seria, nesse caso, a taxa de juro cobrada pela loja?

e) Se você não pudesse pagar à vista, mas pudesse pegar dinheiro emprestado em um Banco, a uma taxa de $5 \%$ ao mês, qual estratégia você utilizaria para comprar o produto? E se a taxa que o Banco te cobrasse fosse de $8 \%$ ao mês?

f) Para você, saber a taxa de juros cobrada pelas instituições é importante na tomada de decisão? Em que aspectos? Por quê?

Fonte: Muniz (2016, p. 232) 


\section{Análise dos resultados: uma leitura dos significados produzidos na tomada de decisão}

Antes de procedermos nossa análise, gostaríamos de apresentar uma reflexão sobre como esse tipo de situação financeira presente na tarefa que analisaremos costuma ser abordada nos livros didáticos de matemática do Ensino Médio, e os descompassos dessa abordagem com a realidade das taxas de juros cobradas no Brasil.

Em todos os livros didáticos de matemática para o EM do PNLD de 2018 temos um capítulo de matemática financeira. Essa questão de tomar a decisão entre comprar à vista ou a prazo é clássica e aparece em quase todos os livros. Mas, infelizmente, ela geralmente aparece associada à taxa de investimento disponível para o comprador, ou seja, os livros induzem os alunos a pensarem nessa decisão entre comprar à vista e a prazo olhando para sua capacidade de investir dinheiro, ou, no jargão econômico, olhando para o quanto o dinheiro vale para quem precisa tomar a decisão. Entendemos que isso pode ser importante, mas que não deveria ser a única e muito menos a primeira forma de abordar esse problema. Entendemos que os livros não convidam os estudantes a pensarem em outras estratégias, em que a taxa de retorno do comprador é apenas uma delas. Ainda no contexto escolar, temos que os professores tendem a reproduzir essa ideia, limitando a análise dessa situação à comparação dos valores atuais de cada uma das opções, descontados à essa taxa. Isso matematicamente e financeiramente não está errado. Mas limita a visão e a complexidade do problema, pois para essa situação, as taxas que permitiriam a compra a prazo ser mais vantajosa que a compra à vista geralmente não estão disponíveis para a grande maioria dos consumidores. Nessa situação por exemplo, a pessoa precisaria ter, pelo menos, uma taxa de retorno de $7 \%$ ao mês em seus investimentos para que a opção de comprar a prazo fosse a mais vantajosa. Mas quem consegue ter esse retorno no Brasil?

Essa tarefa é intencionalmente diferente, pois começa convidando o aluno a pensar o problema e tomar a decisão, sem levar em consideração taxa alguma. Em seguida, convida o aluno a pensar qual a taxa de juros que está sendo cobrada, para, enfim, convidá-lo a refletir sobre possibilidades de financiamento que talvez sejam menos custosas que a oferecida pela loja. Em suma, a questão central aqui é: porque precisamos pegar dinheiro emprestado na loja que optamos por comprar o produto? Por comodidade? Por simplicidade? Por que é geralmente mais barato? Se não temos dinheiro e a compra foi considerada pela pessoa como urgente, por que não tomar o dinheiro necessário para a compra à vista (900 reais) com um custo menor, isto é, a uma taxa de juro menor que $7 \%$ ? 
Essas questões podem contribuir para uma avaliação mais ampla do valor do dinheiro no tempo e das alternativas para se tomar decisão, do que simplesmente achar que somente a taxa de retorno é o único ou o mais importante nessa tomada de decisão, e em último caso, a que vai definir a compra.

Dito isto, passemos a análise das respostas apresentadas pelos estudantes para as duas primeiras perguntas ( $\mathrm{a}$ e b) da tarefa, que foram as seguintes:

Figura 2 - Duas primeiras perguntas da tarefa investigada

a) Qual a melhor decisão para você?

b) O que você faria: compraria à vista ou a prazo? Apresente que aspectos poderiam interferir em sua tomada de decisão.

Fonte: Muniz (2016, p.231)

Todos os estudantes consideraram que o melhor seria pagar à vista, por causa do desconto. Entretanto, outros aspectos emergiram de seus discursos, e vários significados foram produzidos, salientando que essa decisão dependeria da condição financeira do comprador (será que pode pagar 900 à vista?); da capacidade de pagar as duas parcelas; do comprometimento do orçamento para o próximo mês, considerando outras dívidas; do tempo disponível para obter o dinheiro a prazo.

As respostas dadas, tanto nas folhas de registro como as obtidas nos dados capturados em vídeo, evidenciam os fatores que influenciam ou poderiam influenciar a tomada de decisão, conforme sintetizados anteriormente, estão na Tabela 1.

Tabela 1 - Respostas dos estudantes para os itens a e b, apresentadas nas folhas de registro e nos discursos capturados em vídeo

\begin{tabular}{|c|c|c|c|}
\hline Item & Estudante & $\begin{array}{l}\text { Transcrições das } \\
\text { Folhas de registro }\end{array}$ & $\begin{array}{l}\text { Transcrições dos discursos } \\
\text { capturados em vídeo }\end{array}$ \\
\hline Item a & Send & $\begin{array}{l}\text { Depende. Se eu tivesse condições de } \\
\text { pagar à vista, escolheria a opção I, se não } \\
\text { eu pagaria a prazo. }\end{array}$ & \multirow{2}{*}{$\begin{array}{l}\text { Cara, depende. Se eu tiver o dinheiro na hora, é } \\
\text { melhor pagar à vista porque eu pago e tenho desconto. } \\
\text { Mas se não tiver o dinheiro na hora e precisar, como } \\
\text { diz aqui, para trabalhar tenho que pagar a prazo ou } \\
\text { você pega o dinheiro com alguém e paga depois. }\end{array}$} \\
\hline Item $b$ & Send & $\begin{array}{l}\text { Escolher uma opção ou outra depende } \\
\text { muito da disponibilidade de dinheiro. Se } \\
\text { eu tivesse o dinheiro pagaria à vista, e } \\
\text { ainda pagaria mais barato }\end{array}$ & \\
\hline Item a & Sami & $\begin{array}{l}\text { Pagar à vista, pois no total eu pagaria } \\
\text { menos }\end{array}$ & \multirow{2}{*}{$\begin{array}{l}\text { Acho que a melhor decisão é pagar à vista mesmo, } \\
\text { porque só vai pagar o total, vai pagar menos, vai pagar } \\
\mathrm{R} \$ 900 \text { no outro você paga } \mathrm{R} \$ 1000 \text {. Só que eu faria, } \\
\text { eu coloquei que parcelaria. Porque não sei se eu teria } \\
\mathrm{R} \$ 900 \text { assim na hora e se você parcelar também, é, } \\
\text { você vai acabar pagando a mais, mas você vai ter mais } \\
\text { tempo para juntar esse dinheiro. }\end{array}$} \\
\hline Item $b$ & Sami & $\begin{array}{l}\text { Na maioria dos casos eu parcelaria, pois, } \\
\text { dispor de } 900 \text { reais de uma vez é difícil, } \\
\text { além de que teria mais } 30 \text { dias para juntar } \\
\text { dinheiro }\end{array}$ & \\
\hline
\end{tabular}




\begin{tabular}{|c|c|c|c|}
\hline Item a & Stahl & $\begin{array}{l}\text { Dependeria de minha situação financeira. } \\
\text { Seria mais interessante pagar menos à } \\
\text { vista, mas se eu não tivesse condições } \\
\text { seria melhor pagar parcelado }\end{array}$ & \multirow{2}{*}{$\begin{array}{l}\text { Bom é, a letra 'a' eu escrevi que dependeria da } \\
\text { situação financeira da pessoa porque vale apena sim } \\
\text { pegar o desconto à vista, mas se a pessoa não tem } \\
\text { condições disso eu acho que também vale a pena } \\
\text { parcelar o negócio. É, acho que no meu caso el } \\
\text { compraria à vista. Tentaria sei lá, é economizar un } \\
\text { pouco aí quando eu tivesse o dinheiro inteiro para } \\
\text { pagar à vista eu pagaria à vista. Porque eu acho que } \\
\text { vale mais a pena economizar } \mathrm{R} \$ 100 \text {. }\end{array}$} \\
\hline Item $b$ & Stahl & $\begin{array}{l}\text { Eu compraria à vista, tentaria guardar } \\
\text { dinheiro antes para aproveitar o desconto }\end{array}$ & \\
\hline Item a & Carlos & Opção 1 & \multirow{2}{*}{$\begin{array}{l}\text { Botei que pagar à vista é melhor, porque você tem um } \\
\text { valor menor. Você vai economizar R } \$ 100 \text { e na 'b' eu } \\
\text { botei que pagaria à vista também por causa que eu } \\
\text { estou economizando de qualquer jeito, mas eu vou } \\
\text { economizar de qualquer forma. }\end{array}$} \\
\hline Item $b$ & Carlos & $\begin{array}{l}\text { Pagaria à vista por conta do desconto, } \\
\text { porém isso dependeria do meu orçamento }\end{array}$ & \\
\hline Item a & $\mathrm{Lu}$ & $\begin{array}{l}\text { Eu preferiria pagar à vista. Mas se eu } \\
\text { tivesse outras coisas importantes para } \\
\text { comprar, pagaria a prazo }\end{array}$ & \multirow{2}{*}{$\begin{array}{l}\text { Sei lá, à vista você tem o desconto só que assim, eu... } \\
\text { À vista você tem desconto, só que parcelado você tem } \\
\text {... Foi como o Lucas falou, tem mais tempo pra juntar } \\
\text { o dinheiro e de talvez se organizar melhor com outras } \\
\text { dívidas porque você provavelmente não vai pagar só } \\
\text { essa parada }\end{array}$} \\
\hline Item $b$ & $\mathrm{Lu}$ & Vide o item a & \\
\hline Item a & Tom & Sem registro escrito. & \multirow{2}{*}{$\begin{array}{l}\text { Por isso, foi exatamente o que o Bernardo falou que } \\
\text { vale, o que vai contar vai ser a renda da pessoa, a } \\
\text { disponibilidade para que ela compre para que ela } \\
\text { chegue à conclusão que à vista não vai ser problema } \\
\text { para ela, pro resto ou pro mês seguinte, ou se ela tiver } \\
\text { uma renda baixa é melhor ter uma, você pagar a prazo } \\
\text { porque vai ter uma, se tá num trabalho fixo, tem um } \\
\text { dinheiro fixo é mais fácil. Então você já sabe } \\
\text { organizar melhor suas dívidas de acordo com o que } \\
\text { você tem que pagar. }\end{array}$} \\
\hline Item $b$ & Tom & Sem registro escrito. & \\
\hline
\end{tabular}

Fonte: Elaborado a partir de Muniz (2016, p. 234-235)

Identificamos que a principal operação realizada pelos alunos, nesses dois itens, estava associada à obtenção dos valores a serem pagos nas duas situações e, para isso, operaram calculando o valor com desconto, a partir do percentual de desconto apresentado, seguida da comparação desse valor com o desconto (900 reais) com o valor total pago $(2$ de $500=1000)$. A operação utilizada para obter o total pago na segunda opção não levou em consideração qualquer taxa de retorno que poderiam ter disponível, ou seja, essa operação desconsiderou o que haviam aprendido em suas experiências com a matemática financeira ensinada na escola., mas nem por isso suas decisões foram tomadas sem quaisquer critérios.

Reforçamos ainda que a questão orçamentária esteve presente na maioria dos discursos, tanto quando se referiram a serem capazes de comprar à vista, como na capacidade de pagar as duas prestações levando em consideração outras dívidas que não estavam apresentadas. Os participantes, apesar de jovens e, portanto, não terem ingerência sobre o próprio dinheiro e não administrarem totalmente suas finanças, apresentaram preocupações importantes na gestão do dinheiro que prima por não produzir desequilíbrios entre o que entra e o que sai. 
As perguntas dos itens c e d, assim como as dos itens a e b, também estão interligadas. Elas convidam os estudantes a investigarem a taxa de juros embutida nesse financiamento, bem como a determinarem o valor dessa taxa. Conforme ilustra a Figura 3, no terceiro item (c) perguntamos se os estudantes achavam que a loja estava cobrando juros, comparando os 900 (valor à vista) com as duas prestações de 500 (fluxo de pagamentos). Optamos por começar perguntando se eles achavam que a loja estava cobrando juros ao anunciar dessa forma, ao invés de começar afirmando que a taxa existia.

Figura 3 - perguntas c e d da tarefa investigada

c) Comparando o valor à vista com o fluxo de pagamentos a prazo, você acha que a loja está cobrando juros? Justifique sua resposta.

d) Qual seria, nesse caso, a taxa de juro cobrada pela loja?

Fonte: Muniz (2016, p.231)

As respostas dos participantes para esse item (c), registradas em suas folhas, foram as seguintes:

Tabela 3 - Respostas dos estudantes para o item c, apresentadas nas folhas de registro

\begin{tabular}{c|c|l}
\hline Item & Estudantes & \multicolumn{1}{c}{ Transcrições das Folhas de registro } \\
\hline Item c & Send & $\begin{array}{l}\text { Sim, a loja cobra juros escondido. A estratégia é usar como base de preço o } \\
\text { valor a prazo e não à vista. }\end{array}$ \\
\hline Item c & Sami & Sim, pois pagar a prazo significa pagar mais, no caso. \\
\hline Item c & Stahl & $\begin{array}{l}\text { Sim, na realidade ao pagar à vista com desconto você estaria pagando o valor } \\
\text { real do produto e ao pagar parcelado sem desconto você estaria pagando o } \\
\text { valor real mais os juros. }\end{array}$ \\
\hline Item c & Carlos & $\begin{array}{l}\text { Sim. Se for comparar o valor à vista, eu deixaria de pagar 900 para pagar } \\
1.000 \text { (parcelado em duas vezes) }\end{array}$ \\
\hline Item c & Lu & $\begin{array}{l}\text { Sim, mas não sob o nome de juros. Se a loja pode cobrar 900, sem que haja } \\
\text { perda no lucro, existem taxas sendo cobradas no valor de 1000. }\end{array}$ \\
\hline Item c & Tom & Sim. Se pensarmos no marketing, sim. \\
\hline
\end{tabular}

Fonte: Muniz (2016, p. 236)

A diferença de valores foi o principal objeto constituído na produção de conhecimento, ou seja, para dizerem que acreditavam que havia juros. Assim, o argumento central foi "se há diferença de valores então há uma taxa de juros", ou, de outra forma, "pagar a prazo significa pagar mais".

O próximo passo seria encontrar essa taxa e isso foi direcionado pelo item d, que pergunta justamente isso. Comecemos nossa análise pela solução apresentada por Sami, representada na Figura 4 a seguir. 
Figura 4 - Solução de Sami para o item d da Tarefa apresentada

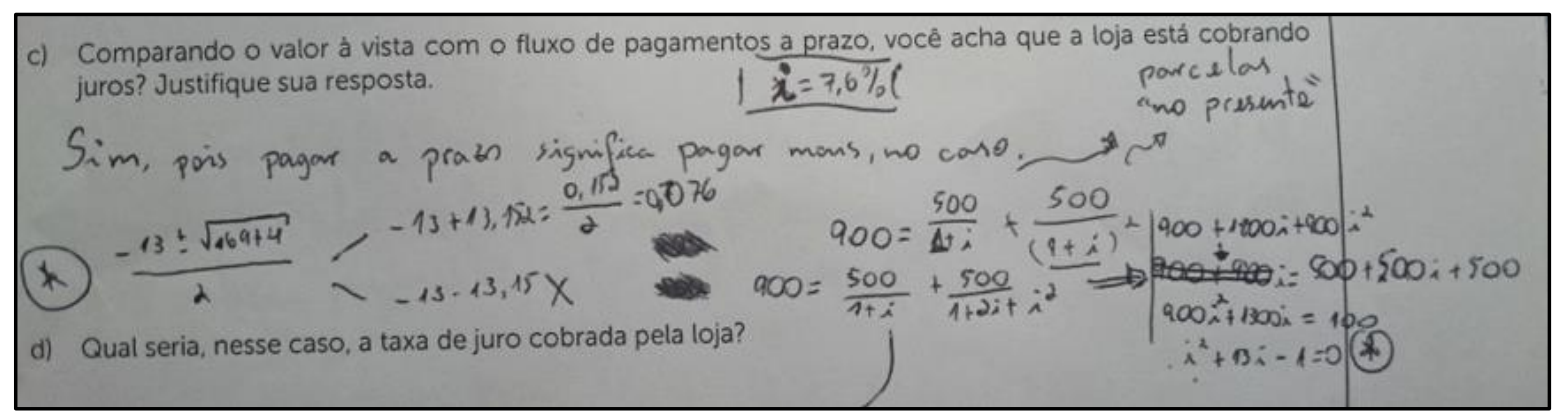

Fonte: Muniz (2016, p. 237)

Essa solução consiste em transportar cada uma das prestações de 500 para a data zero, ou seja, para o momento da compra, e igualar esses valores presentes a 900. Isso é o mesmo que dizer a que taxa, 900 reais na data zero, se equivalem a duas prestações de 500, sendo pagas após 1 e 2 meses, respectivamente. Sami está usando aqui suas experiências com a matemática financeira abordada na escola, em especial a noção de equivalência de capitais, para descobrir a que taxa 900 reais se transformam em duas parcelas de 500 reais. Sami, ao operar usando a equivalência de capitais, construiu um modelo matemático que resultou em uma equação do segundo grau.

Olhando de outra forma, o que Sami fez foi determinar qual é a taxa que me permite repartir 900 hoje, em duas partes, de modo que uma parte se transforme em 500 daqui a 1 mês, e em 500 daqui a 2 meses, com a taxa incidindo sobre dois saldos devedores, pois estamos pensando em duas dívidas (partes de 900) que serão pagas daqui a 1 e 2 meses, respectivamente. O quadro a seguir ilustra a relação entre essa ótica e a solução de Sami.

\section{Quadro 2 - Uma possível Representação Temporal para a Solução de Sami}

\begin{tabular}{|c|c|c|}
\hline 0 & 1 & 2 \\
\hline$\frac{500}{f}$ & $\longleftarrow 500$ & \\
\hline$\frac{500}{f^{2}}$ & $\longleftarrow$ & 500 \\
\hline
\end{tabular}

Fonte: Muniz (2016, p.240)

Assim, temos que 500/f é a parte da dívida de 900, na data zero, que daqui a 1 mês valerá 500.f/f $=500$ reais, e 500/f ${ }^{2}$ é, na data zero, o valor da outra parte da dívida de 900 que daqui a 2 meses valerá $500 . \mathrm{f}^{2} / \mathrm{f}^{2}=500$ reais.

Identificamos várias resoluções diferentes da apresentada por Sami, em que diferentes objetos foram constituídos, bem como outras operações com suas próprias lógicas, segundo preconiza 
o modelo dos campos semânticos, conforme se pode na Figura 6. Procuramos identificar tais objetos, as operações e suas lógicas.
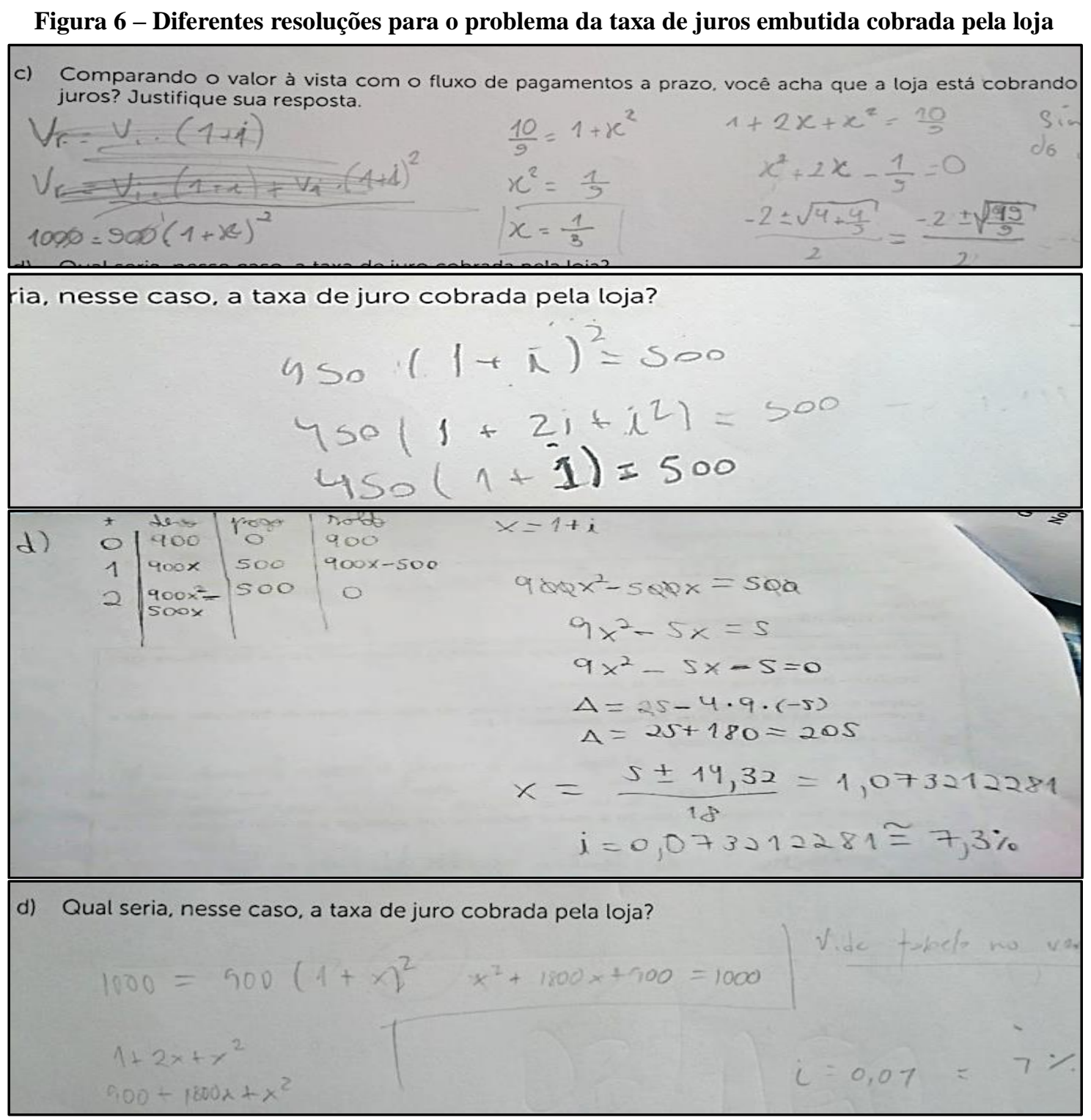

Fonte: Muniz (2016, p. 241)

Na primeira resolução, temos que o estudante constitui como objetos o valor à vista, como sendo o valor presente da dívida, e a soma das parcelas como o valor futuro da dívida. Pela ótica do MCS, nos termos que definimos neste texto, dizemos que ele está operando no campo semântico da adição de capitais $(500+500)$, desconsiderando o valor do dinheiro no tempo. Por outro lado, uma vez constituídos esses objetos, a operação entre eles é outra, pois considera a transformação do dinheiro no tempo em que a taxa incide sobre o valor da etapa anterior (que não é o saldo devedor real), operando assim em outro campo semântico, que denominamos de campo semântico da equivalência de capitais. 
Para esse estudante, em um momento a lógica da operação para gerar os 1000 desconsidera a taxa na transformação do dinheiro no tempo; logo em seguida, a operação é outra, pois a lógica muda. Agora a transformação leva em consideração a taxa para transformar o valor do dinheiro no tempo. Essa alternância desses dois campos semânticos foi vista em diversos momentos ao longo dos encontros, o que revela algumas interfaces e diferenças entre as ideias matemáticas e financeiras presentes em diversas situações financeiras.

Na segunda parte da figura 5 há uma estratégia semelhante à apresentada na primeira, só que com a metade dos valores. Em nossa análise, há apenas duas diferenças. A primeira está nos objetos iniciais constituídos, em que o estudante compara 450 (metade de 900) com 500 (metade da soma das prestações); a segunda está em operar no campo semântico da equivalência de capitais com esses dois valores, desconsiderando os outros valores.

Na terceira parte da figura 5 há uma solução em que o estudante, após a intervenção e sugestões do pesquisador, opera permanentemente no campo semântico da equivalência de capitais.

$\mathrm{Na}$ quarta solução temos que a lógica da operação coincide com a segunda lógica apresentada na primeira solução.

Essas quatro soluções nos permitiram identificar, a partir da lógica do MCS, que os estudantes estavam diante de um obstáculo epistemológico, ou seja, se não operassem em outra direção não conseguiriam obter a taxa cobrada pela loja no financiamento. Após uma intervenção do pesquisador, conforme detalhada em Muniz (2016, p. 241), os estudantes conseguiram operar de modo a obter a taxa de juros embutida no financiamento.

Nesse momento, julgamos importante fazer uma conexão entre o que observamos aqui e o contexto do ensino de matemática financeira na sala de aula de matemática no Ensino Médio. A nossa prática docente tem nos mostrado que o problema de encontrar taxas em financiamentos de parcelas iguais costuma ser considerado difícil pelos alunos, ainda que disponham de calculadoras científicas (não programáveis). Nosso estudo apresentou evidências dessa complexidade e, consequentemente, dificuldade tanto na elaboração de um modelo matemático que lhes proporcionasse obter a taxa, quanto na resolução desse modelo.

Antes de passarmos para as duas últimas perguntas, vamos analisar um momento chave, que está ainda relacionado às perguntas $\mathrm{c} e \mathrm{~d}$.

Em um momento do encontro, Sami apresenta dois pontos de vista sobre a situação das lojas concederem desconto à vista para compras a prazo, conforme registrado na transcrição a seguir.

Tabela 4 - Transcrição de um diálogo entre Sami e o pesquisador sobre taxas de juros embutidas

\begin{tabular}{l|l|l}
$00: 21$ & Pesq & Você acha que a loja está cobrando juros?
\end{tabular}




\begin{tabular}{c|c|l}
\hline 00:25 & Sami & Eu acho que sim. \\
\hline 00:27 & Sami & $\begin{array}{l}\text { Porque você tá pagando a prazo, você vai tá pagando mais do que você pagaria à } \\
\text { vista. Então, desse ponto de vista você poderia dizer que sim, porque se você } \\
\text { pagasse o valor cheio do início, x, e no final de tudo se você passar vai dar um 'x' } \\
\text { maior. }\end{array}$ \\
\hline $00: 49$ & Pesq & Porque você falou desse ponto de vista? Teria algum outro? \\
\hline $00: 52$ & Sami & $\begin{array}{l}\text { Porque se você olhar pelo ponto de vista do marketing da loja, vc tem: estou } \\
\text { querendo te dar um desconto aqui, mas o valor na verdade é esse... }\end{array}$ \\
\hline $01: 08$ & Pesq & $\begin{array}{l}\text { Entendi. Então o ponto de vista da loja não tem juros, tem desconto? [Lucas: é tem } \\
\text { desconto], do ponto de vista do comprador tem juros? }\end{array}$ \\
\hline
\end{tabular}

Fonte: Muniz (2016, p. 243)

O primeiro ponto de vista apresentado por Sami é o de que a loja tem um produto que custa 900 à vista e cobra juros no financiamento. No segundo ponto de vista, ele vê a loja tentando passar a ideia de que está concedendo um desconto sobre o preço do produto (1000 reais), usando uma mensagem (chamada de marketing por ele) de que está oferecendo uma vantagem para o comprador. Em seguida Lu comenta sobre preço real (1000) e um preço "real real" (900), conforme se pode ver na Tabela 5.

Tabela 5 - Transcrição de um diálogo entre Lu e o pesquisador sobre taxas de juros embutidas

\begin{tabular}{c|c|l}
\hline $01: 13$ & Lu & $\begin{array}{l}\text { O Ivail, é que no enunciado fala que o preço da tabela é mil reais, valor real do } \\
\text { produto é mil reais }\end{array}$ \\
\hline $01: 21$ & Pesq & Valor real. \\
\hline $01: 24$ & Lu & $\begin{array}{l}\text { É! Só que na verdade se a loja está te dando desconto e eles não estão perdendo } \\
\text { lucro com isso, significa que o valor real do produto na verdade é novecentos reais }\end{array}$ \\
\hline $01: 34$ & Pesq & $\begin{array}{l}\text { Ou seja, o preço real real [Lu: é novecentos] é novecentos, mas o preço real é mil? } \\
\text { Mas o real real é novecentos, é isso? }\end{array}$ \\
\hline $01: 38$ & Lu & Isso! \\
\hline
\end{tabular}

Fonte: Muniz (2016a, p. 244)

Assim, além dos aspectos matemáticos já identificados até aqui na tomada de decisão, tais como o valor do desconto, a taxa de juros embutida, alternativas financeiras envolvendo parcelas e taxas, e também aos não matemáticos, tais como vontade de comprar, capacidade de se planejar, paciência, etc, emergem nesse momento mais um aspecto não matemático, qual seja, como o comprador vê a situação: vantagem no desconto, ou cobrança de juros no parcelamento, e como essa "simples" mudança na formulação e apresentação das informações pode influenciar o comportamento do consumidor diante dessa situação.

Nesse ponto da nossa análise, vamos olhar para essa situação a partir de uma outra lente, através da psicologia econômica, para ampliarmos o entendimento sobre o que está envolvido nessa situação explorada pelos estudantes. Veremos que há alguns aspectos comportamentais que podem 
ser levados em consideração pelas lojas e instituições financeiras na montagem dessas estratégias, incluindo a forma como comunicam ao consumidor diferentes alternativas de pagamento, bem como algumas noções que podem nos ajudar a entender alguns comportamentos apresentados nessa situação.

O primeiro é baseado nas ideias de Dan Ariely (2008, p. 2) de que os humanos raramente fazem escolhas absolutas, encarando suas decisões de maneira relativa, comparando localmente as alternativas e se concentrando na vantagem relativa de uma coisa sobre a outra. Como isso se aplica em nossa tarefa? A presença do valor 1000 pode ser vista como apenas um chamariz, isto é, um valor de referência para, nesse caso, servir de base de comparação para que o consumidor se sinta levando uma vantagem ao pagar 900, ou seja, gerando nele a sensação de que ele está levando vantagem pois a loja está abrindo mão de 100 reais para que ele pague menos.

$\mathrm{O}$ segundo aspecto é baseado na ideia de enquadramento de resultados (TVERSKY; KAHNEMAN, 1981), em que as pessoas podem tomar diferentes decisões, para uma mesma opção, dependendo da forma como foi formulada. Essas atitudes diferentes decorrem do que esses estudiosos chamam de efeitos de formulação. Tais efeitos de formulação, segundo Kahneman (2011, p. 549), apesar de poderem ocorrer fortuitamente, sem ninguém ter consciência do impacto do quadro na decisão final, também podem ser explorados deliberadamente para manipular a atratividade relativa das opções. Um exemplo disso, segundo Thaler (1980), é a forma como lobistas da indústria de cartão de crédito insistiam para que as diferenças de preço entre compras pagas no dinheiro e no cartão de crédito fossem classificadas como desconto para pagamento em dinheiro e não como sobre taxa do cartão. Sobre essa situação, Kahneman (2012, p. 549) comenta:

As duas classificações enquadram a diferença de preço como um ganho ou como uma perda ao determinar implicitamente o preço mais baixo ou o mais alto como normal. Como as perdas assomam maiores do que os ganhos, os consumidores apresentam menor probabilidade de aceitar uma sobretaxa do que abrir mão de um desconto.

Esse exemplo último nos parece bem similar ao efeito de formulação, apresentado por Kahneman e Tversky, uma forma de avaliar a estratégia comumente usada pelas lojas de oferecer descontos para pagamento à vista, o que seria mais atrativo ao consumidor.

Figura 7 - Uma mesma situação financeira representada por dois enquadramentos diferentes

\begin{tabular}{|l|l|}
\hline \multicolumn{1}{|c|}{ Cenário A } & \multicolumn{1}{|c|}{ Cenário B } \\
\hline $\begin{array}{l}\text { Opção I - 900 à vista } \\
\text { Opção II - parcelado em 2 vezes com juros } \\
(2 \times 500)\end{array}$ & $\begin{array}{l}\text { Opção I - } 1000 \text { com } 10 \% \text { de desconto à vista } \\
\text { Opção II - parcelado em 2 vezes com juros }(2 \times 500)\end{array}$ \\
\hline
\end{tabular}

Fonte: Muniz (2016, p. 246) 
Nos dois casos, os valores pagos são os mesmos. Mas será que as duas formulações são vistas da mesma maneira pelas pessoas? São enquadradas da mesma forma? Segundo os estudos de Kahneman (2011), dentre outros, as pessoas veem as duas opções como diferentes, apesar de serem equivalentes do ponto de vista financeiro para o comprador. Segundo os alunos presentes nesse encontro, também não são vistas da mesma maneira.

Não estamos defendendo que todas as vezes que nos deparamos com tal situação estejamos diante de uma ação deliberada do agente do mercado em questão (loja, banco, seguradora, etc) em se valer do enquadramento das pessoas a diferentes formulações para obter lucro maior. Estamos dizendo, entretanto, que os preços anunciados e a forma de pagamento em muitas situações podem representar ações do mercado que buscam cobrar juros das pessoas sem que percebam, bem como fazendo-as pensar que estão diante de um benefício.

Por último gostaríamos de comentar que os estudantes, em certa medida, apresentaram em suas análises algumas dessas características comportamentais que acabamos de citar, demonstrando que, apesar de jovens, eles apresentaram uma gama de aspectos relacionados à tomada de decisão, incluindo os comportamentais, que retratam muito bem a realidade de consumo brasileira. Os AEFE que construíram, e no qual estavam inseridos, certamente os estimularam a analisarem, interagirem e refletirem de maneira colaborativa sobre tais situações, aproveitando suas experiências pessoais em diversos momentos.

Finalmente, vamos analisar as decisões dos estudantes para os cenários criados nos itens $\boldsymbol{e}$ e $\boldsymbol{f}$, que envolviam um novo elemento a ser levado em consideração na tomada de decisão. As perguntas foram as seguintes:

Figura 8 - perguntas e e $f$ da tarefa investigada

e) Se você não pudesse pagar à vista, mas pudesse pegar dinheiro emprestado em um Banco, a uma taxa de $5 \%$ ao mês, qual estratégia você utilizaria para comprar o produto? E se a taxa que o Banco te cobrasse fosse de $8 \%$ ao mês?

f) Para você, saber a taxa de juros cobrada pelas instituições é importante na tomada de decisão? Em que aspectos? Por quê?

Fonte: Muniz (2016, p.245)

As respostas dos participantes registradas em suas folhas, para os itens acima apresentados, foram as seguintes:

Tabela 6 - Respostas dos estudantes para os itens e e f, apresentadas nas folhas de registro

\begin{tabular}{c|c|l}
\hline Item & Estudante & \multicolumn{1}{c}{ Transcrições das Folhas de registro } \\
\hline Item e & Send & $\begin{array}{l}\text { Se fosse a taxa de } 5 \% \text { eu pegaria do Banco; se fosse de } 8 \% \text { não } \\
\text { pegaria. } 5 \%<7 \%<8 \% .\end{array}$ \\
\hline
\end{tabular}




\begin{tabular}{|c|c|c|}
\hline Item $\mathrm{f}$ & Send & $\begin{array}{l}\text { Sim, sabendo a taxa de juros, podemos escolher de forma mais } \\
\text { consciente o modo de pagar. }\end{array}$ \\
\hline Item e & Sami & $\begin{array}{l}\text { A uma taxa de } 5 \% \text {, pegaria dinheiro com o banco, pois com duas } \\
\text { parcelas pagaríamos menos. }\end{array}$ \\
\hline Item $\mathrm{f}$ & Sami & $\begin{array}{l}\text { Sim, pois envolve, no final, tomar decisões mais conscientes. O } \\
\text { problema é quando se tem a informação mas não se sabe o que fazer } \\
\text { com e a partir dela. }\end{array}$ \\
\hline Item e & Stahl & $\begin{array}{l}\text { A uma taxa de } 5 \% \text {, valeria a pena pagar à vista. Já a uma taxa de } 8 \% \\
\text { ao mês não valeria já que, ao final de } 2 \text { meses, o valor da dívida com } \\
\text { o banco ultrapassaria o valor do produto na opção } 2 \text {. }\end{array}$ \\
\hline Item $\mathrm{f}$ & Stahl & $\begin{array}{l}\text { Sim, pois assim você pode planejar diferentes alternativas para pagar } \\
\text { alguma dívida, chegando a que melhor se adequa a sua situação } \\
\text { financeira. }\end{array}$ \\
\hline Item e & Carlos & Com a taxa de $5 \%$ vale a pena. Já com a de $8 \%$ não. \\
\hline Item $\mathrm{f}$ & Carlos & $\begin{array}{l}\text { Sim. No aspecto do valor final a ser pago para poder achar o valor } \\
\text { mais em conta. Porque assim o gasto fica menor. }\end{array}$ \\
\hline Item e & $\mathrm{Lu}$ & $\begin{array}{l}\text { Quando a taxa é } 5 \% \text {, vale a pena pegar dinheiro emprestado em um } \\
\text { Banco. Quando é } 8 \% \text {, não vale a pena já que a taxa é maior que a da } \\
\text { loja. }\end{array}$ \\
\hline Item $\mathrm{f}$ & $\mathrm{Lu}$ & $\begin{array}{l}\text { Sim, pois eu vou procurar pagar pelo modo que me dará menos } \\
\text { prejuízo. }\end{array}$ \\
\hline Item e & Tom & Sem registro escrito. \\
\hline Item $\mathrm{f}$ & Tom & $\begin{array}{l}\text { Personalidade. O que influencia as pessoas é a personalidade de cada } \\
\text { negócio. A personalidade é o ponto chave para a decisão de cada } \\
\text { indivíduo. }\end{array}$ \\
\hline
\end{tabular}

Fonte: Elaborado a partir de Muniz (2016, p. 234-235)

Tais respostas revelam que praticamente todos eles, com exceção de Tom, inicialmente, constituem as taxas cobradas como objetos com os quais passam a operar, comparando-as diretamente com as taxas disponíveis no Banco, isso quando entenderam que o prazo e o tipo de financiamento poderia ser o mesmo em ambas instituições.

Disseram que escolheriam pegar o empréstimo com o Banco caso a taxa fosse 5\%, e não escolheriam caso a taxa fosse $8 \%$, tomando como referência taxa de $7 \%$ que eles calcularam, cobrada de forma embutida pela loja no parcelamento em duas vezes "sem juros". Aqui os aspectos matemáticos foram preponderantes na tomada de decisão apresentada pelos alunos.

\section{Considerações finais}

Apresentamos nesse texto um recorte de um estudo sobre a tomada de decisão em Ambientes de Educação Financeira Escolar, em que jovens estudantes do ensino médio analisavam situações financeiras por meio de tarefas didáticas. 
Foram analisados aspectos matemáticos e não matemáticos, na perspectiva de Muniz (2016), para uma SEF muito comum no comércio brasileiro entre comprar à vista (com desconto) ou a prazo em parcelas mensais e iguais ("sem juros").

Para essa análise utilizamos algumas noções e categorias do MCS, em especial a constituição de objetos, as operações realizadas com eles e suas lógicas, bem como alguns resultados da Psicologia Econômica, em nosso caso, a questão do enquadramento e da aversão à perda.

Identificamos que os estudantes consideram a compra à vista com desconto mais atraente do que a compra a prazo, fundamentando inicialmente seus argumentos nos valores a serem pagos, e, portanto, desconsiderando quaisquer eventuais taxas de retorno disponíveis ao investidor. A análise dos dados nos permitiu identificar que outros aspectos emergiram de seus discursos, e vários significados foram produzidos, salientando que essa decisão dependeria da condição financeira do comprador; da capacidade de pagar as duas parcelas; do comprometimento do orçamento para o próximo mês, considerando outras dívidas que eventualmente teriam; do tempo disponível para obter o dinheiro a prazo, e também com a real necessidade de compra do produto. Apesar de jovens, estudantes do grupo pesquisado pensaram e consideraram aspectos matemáticos e não matemáticos na tomada de decisão.

Foi consenso para o grupo de estudantes investigado que conceder descontos para pagamentos à vista é uma maneira sutil de se cobrar juros a prazo. Observamos, a partir dos registros escritos, que descobrir essa taxa não se mostrou uma tarefa fácil, pois só um aluno conseguiu encontrar a taxa que a loja de fato estava cobrando na comparação das opções de pagamento, sem a intervenção do pesquisador. Na perspectiva do MCS, identificamos, nessa parte da tarefa, um obstáculo epistemológico na obtenção dessa taxa, sendo a intervenção do pesquisador necessária para os estudantes pensassem em uma direção diferente da que estavam pensando, para enfim obterem a taxa, utilizando as noções de matemática financeira e a calculadora científica disponíveis.

Mais importante que isso, em nossa visão, foi a apresentação de diferentes operações para os objetos matemático financeiros constituídos pelos estudantes para a descoberta dessa taxa, com suas lógicas particulares, evidenciando de que lugar estavam falando. Isso também contribuiu para a formulação de intervenções individuais que convidavam os estudantes a pensar em outras direções.

Nossa investigação evidenciou que os estudantes, de posse da taxa de juros embutidos cobrada na situação, não apenas a levaram em consideração para tomar decisão como souberam usála de forma otimizada do ponto de vista financeiro para escolher novas opções de financiamento de menor custo para eles.

De uma forma geral, esse estudo pode contribuir para as aulas de matemática financeira na Educação Básica, ampliando a visão sobre essa situação que geralmente é abordada de forma bem 
limitada e distante da realidade econômica brasileira. A pluralidade de objetos constituídos, operações e lógicas dessas operações podem indicar possíveis formas de pensar de outros estudantes, contribuindo assim para a prática docente. Além disso as questões comportamentais, que muitas preponderam sobre as matemáticas, estiverem presentes em diversos momentos, de modo que este estudo contribui não apenas para a análise dos aspectos não matemáticos, mas também para um convite a pensar SEF de forma integrada, em que aspectos matemáticos e não matemáticos estão interligados, conectados.

Esperamos que este texto contribua, com professores e pesquisadores do tema, para a implementação de ações de Educação Financeira em uma perspectiva crítica - na não aceitação imediata das questões postas conectada a uma mobilização das experiências matemáticas na busca pela compreensão e construção de soluções para o problema apresentado e na emergência de alternativas às soluções comuns.

Finalmente, almejamos que nossa produção de significados para os significados produzidos pelos estudantes seja mais um exemplo do modelo dos campos semânticos posto em movimento, pois é assim que o Rômulo gostava de vê-lo. E aqui destaco dois movimentos: um movimento que pode ajudar o professor da educação básica a compreender diferentes formas de pensar e a estimular que tais diferenças são tão importantes, quanto o domínio de técnicas e métodos de resolução de problema. Neste texto o MCS nos ajudou a entender a importância de se dar voz ao outro e a tentar compreender os significados desses discursos. Há situações aqui que podem aparecer em qualquer sala de aula de matemática da educação básica.

Outro movimento é o do MCS na pesquisa. Muito embora o MCS tenha sido para o autor deste texto mais do que um referencial teórico-metodológico, temos que esse referencial defende uma crença de que os conhecimentos não são estáticos, não estão em livros, na internet, e muito menos no quadro da sala de aula. Defende ainda que a linguagem da ciência, da economia, da medicina e de tantas outras áreas científicas são formas, dentre muitas outras, de se expressar os conhecimentos produzidos pelas pessoas. A linguagem dos alunos ao tratar de temas econômicos e financeiros nos muitos discursos transcritos nesse texto (e isso foi intencional) mostra que a multiplicidade de direções é a norma quando pensamos na aprendizagem humana, ou seja, este texto em parte é o MCS em movimento para a pesquisa, e por isso entendemos que o movimento do MCS não pode parar. Ele tem sido, em nossas pesquisas, bem como na prática docente, uma das formas mais impressionantes e ricas de fazer a leitura do pensamento dos estudantes, e a vê-los de forma construtiva e não destrutiva, pelo que não tem, não conseguem ou (inda) não mostraram. Que o MCS e as ideias aqui apresentadas contribuam para ampliar o pensamento e a liberdade de todos aqueles que buscam 
ensinar para ampliação da liberdade, da crítica e do bem social, por meio da matemática e de outras produções humanas.

\section{Referências}

APREA, C. et al. International Handbook of Financial Literacy. New York: Springer, 2016. CAMPOS, A. B. Investigando como a Educação Financeira Crítica pode contribuir para tomada de decisões de consumo de jovens indivíduos-consumidores. Dissertação (Mestrado). Universidade Federal de Juiz de Fora (UFJF), Juiz de Fora, 2013.

KAHNEMAN, D. Rápido e Devagar: duas formas de pensar. Rio de Janeiro: RJ: Objetiva, 2012.

LINS, R. C. Por que discutir teoria do conhecimento é relevante para a Educação Matemática. In: Bicudo, M. A. V. (org.). Pesquisa em Educação Matemática: concepções e perspectivas. São Paulo: Editora da UNESP, .75-94.

LINS, R. C. O. modelo dos campos semânticos: estabelecimentos e notas de teorizações. In: ANGELO, C. L. et al. (Orgs). Modelo dos Campos Semânticos e Educação Matemática - 20 anos de história. São Paulo: Midiograf, 2012

LINS, R. C.; GIMENEZ, J. Perspectivas em aritmética e álgebra para o século XXI. Campinas, SP: Papirus, 1997.

LOERWALD, D.; STEMMANN, A. Behavioral Finance and Finance Literacy: Educations Implications of Biases in Financial Decision Making. In Aprea et al. (Ed), International Handbook of Financial Literacy. Springer. 2016.

MUNIZ, I. Jr. Econs ou Humanos? Um estudo sobre a tomada de decisão em Ambientes de Educação Financeira Escolar. 418p. Tese de Doutorado, UFRJ/COPPE, Universidade Federal do Rio de Janeiro, Brasil. 2016.

PESSOA, C. A. S. Educação Financeira: O que tem sido produzido em mestrados e doutorados defendidos entre 2013 e 2016 no Brasil? In: CARVALHÊEO, J.; CARVALHO, M. V.; ARAUJO, F. (orgs.). Produção de conhecimentos na Pós-graduação em educação no nordeste do Brasil: realidades e possibilidades. Teresina: EDUPI, 2016.

POWELL, A. B (org). Métodos de Pesquisa em Educação Matemática - Usando escrita, vídeo e internet. Mercado de Letras. Rio de Janeiro, 2015.

ROLIM, M.R.L.B; MOTA, M.S. O estado da arte das pesquisas em matemática financeira nos programas de mestrado e doutorado da área de ensino da Capes. São Paulo: Educação Matemática Pesquisa, v.16, n.2, pp. 537-556, 2014.

SILVA, A. M. Sobre a Dinâmica da Produção de Significados para a Matemática. 243p. Tese de Doutorado - Universidade Estadual Paulista, Rio Claro, SP. 2003.

SILVA, A.M.S; POWELL, A.B. Um programa de Educação Financeira para a Matemática Escolar da Educação Básica. In XI Encontro Nacional de Educação Matemática, 11., 2013, Paraná. Anais do XI ENEM ... Paraná, Brasil: 2013, p. 1-17.

SAITO, A. T. Uma contribuição ao desenvolvimento da educação em finanças no Brasil. Dissertação de Mestrado. FEA/USP - São Paulo, 2008.

THALER, R.H; SUNSTEIN, C.R. Nudge. Improving decisions about health, wealth and happiness. Springer. 2008. 
TVERSKY, A.; KAHNEMAN, D. The framing of decisions and the psychology of choice. Science, New Series, 211(4481), 453-457. 1981.

XU, L.; ZIA, B. Financial Literacy around the Word. An overview of the evidence with practical suggestions for the way forward. The World Bank, Development Research Group, Finance and Private Sector Development Team. 2012.

Submetido em abril de 2018

Aprovado em maio de 2018 